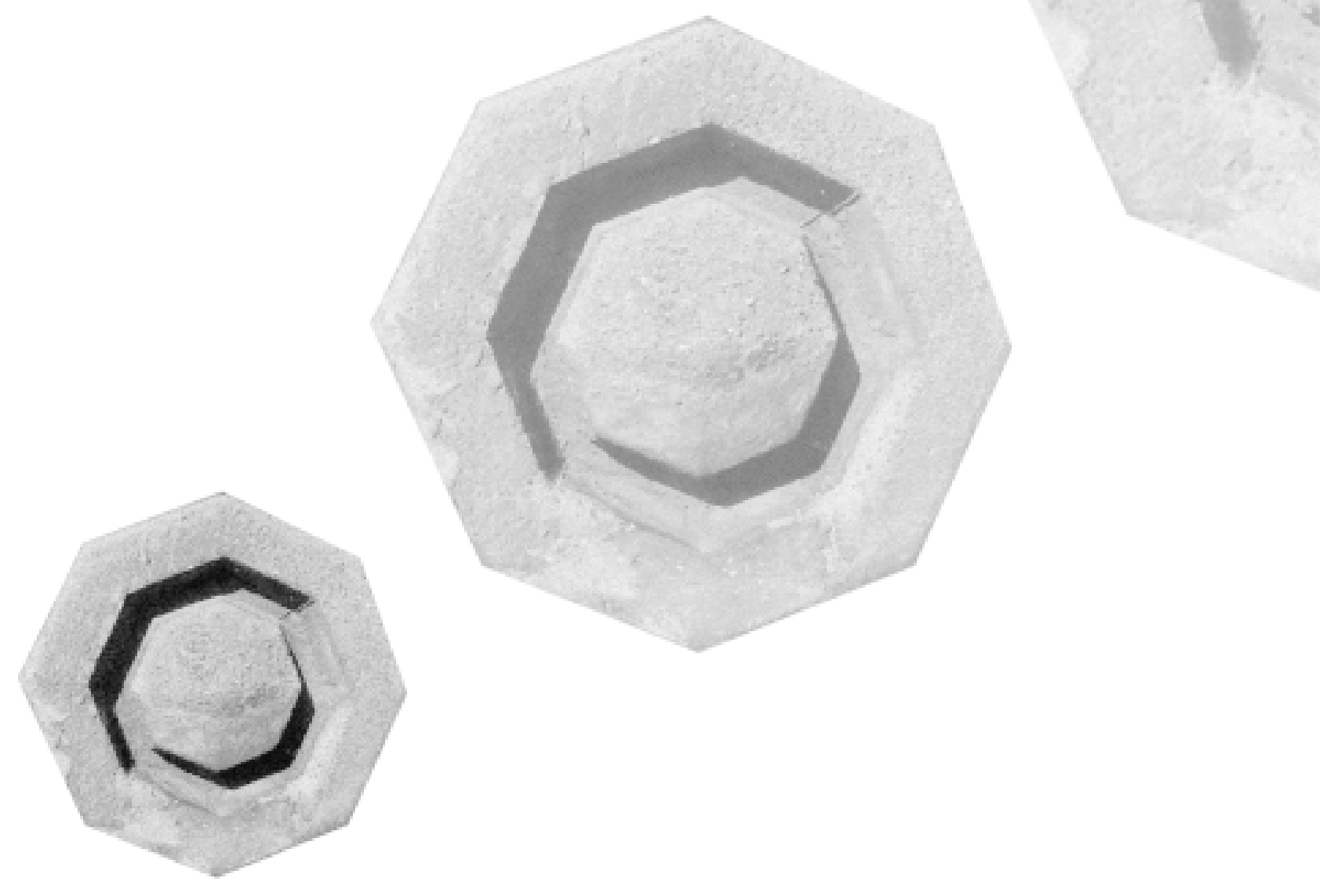




\section{Aulas de cirurgia no centro da América do Sul (1808-16)}

\author{
Surgical classes in the \\ middle of South \\ America (1808-16)
}

JESUS, N. M. de: 'Aulas de cirurgia no centro da América do Sul (1808-16)'.

História, Ciências, Saúde-Manguinhos, vol. 11(1), 93-106, jan.-abr. 2004.

O presente artigo tem como objetivo analisar as propostas de aulas de cirurgia na capitania de Mato Grosso, ampliando as reflexões sobre a arte de curar no período colonial. As propostas dessas aulas estão inseridas em um conjunto de medidas tomadas no período e refletem a preocupação das autoridades com a saúde do bem comum.

PALAVRAS-CHAVE: ilustração, história da medicina, aula de cirurgia, Mato Grosso.

JESUS, N. M. de: 'Surgical classes in the middle of South America (1808-16)'.

História, Ciências, Saúde-Manguinhos, vol. 11(1): 93-106, Jan.-Apr. 2004.

As a contribution to reflections on the art of curing during the colonial period, the article analyzes the proposal to hold surgical classes in the captaincy of Mato Grosso. This proposal was part of a set of measures taken during the period, measures that reflected the government authorities' concern with the public health.

KEYWORDS: illustration, history of medicine, surgical classes, Mato Grosso.
Nauk Maria de Jesus

Mestre em história pela Universidade Federal de Mato Grosso

Rua Caetano Santana, 74 Porto

78020-240 Cuiabá — MT Brasil jnauk@hotmail.com 
${ }^{1}$ Plano de Aula Régia de Anatomia e Cirurgia de Vila Bela. Mss., Lata 1808B, APMT.

${ }^{2}$ Regulamento Provisional para a Aula de Cirurgia na Vila Real do Senhor Bom Jesus do Cuiabá. Livro de registro de instruções, ordens, regulamentos, representações e resoluções (1815-818), nC-60, fólio 78, APMT.

E ste texto é o resultado de reflexões que vêm sendo desenvolvidas sobre a arte de curar, no centro da América do Sul durante o período colonial. Entre as fontes localizadas para compor esse universo estão o Plano de Direção de Anatomia e Cirurgia de Vila Bela ${ }^{1}$ de 1808 e o Regulamento Provisional para a Aula de Cirurgia em Cuiabá de 1816. ${ }^{2}$ Adoto a expressão 'centro da América do Sul' porque ela abrange as repartições do Mato Grosso e de Cuiabá, pertencentes à capitania de Mato Grosso. A primeira delas localiza-se entre a margem ocidental dos rios Paraguai e Guaporé e a segunda, entre a margem oriental do rio Paraguai e o rio Araguaia.

A repartição do Mato Grosso tinha como principal núcleo urbano a Vila Bela da Santíssima Trindade, fundada em 1752 para ser a sede do governo da capitania de Mato Grosso, desmembrada de São Paulo em 1748. Já a repartição de Cuiabá tinha como principal núcleo a Vila Real do Senhor Bom Jesus do Cuiabá, ocupada desde 1719 pelos colonizadores. Eram nessas duas importantes vilas da capitania que iriam funcionar as aulas de cirurgia.

Na década de 1960, Humberto Marcílio transcreveu o Plano de Aula de Vila Bela, datado de 17 de outubro de 1808 (1963, p. 30). Em nossa pesquisa, localizamos esse plano no Arquivo Público de Mato Grosso (APMT), datado no entanto de 15 de julho de 1808. Comparando-se as duas transcrições, percebem-se outros aspectos divergentes além das datas, como irá se demonstrar a seguir.

Lycurgo Santos Filho (1991, p. 27), que possui um amplo estudo sobre a história da medicina no Brasil, menciona, dentre outras aulas de cirurgia que existiram na América portuguesa, a aula de cirurgia de Vila Bela:

[...] instituído pelo capitão general João Carlos d' Oeynhausen [...], não se sabendo entretanto se aula de cirurgia criada pela portaria de 16/12/ 1816 e aprovada pelo Aviso de 12/07/1817 foi realmente prelecionada. De positivo sabe-se que em 04/06/1817 foram estabelecidos prêmios mensais para os alunos matriculados (Santos Filho, 1991, p. 27).

A afirmação de Santos Filho tem um certo sentido; no entanto, em 16 de dezembro, foi criada uma aula de cirurgia não na Vila Bela, mas na Vila Real.

\section{TABELA I}

AULAS DE CIRURGIA NA AMÉRICA PORTUGUESA

\begin{tabular}{llll}
\hline \multicolumn{1}{c}{ CURSO } & \multicolumn{1}{c}{ DATA } & \multicolumn{1}{c}{ LOCAL } & CIRURGIÃO-MOR \\
\hline Anatomia e cirurgia & 1790 & Santa Casa do Rio de Janeiro & Antonio José Pinto \\
$\#$ & 1805 & Hospital Real Militar do Morro do Castelo & Antonio José Pinto \\
$\#$ & Fins do XVIII? & Hospital Militar de Vila Rica & Antonio José Vieira de Carvalho \\
Cirurgia & $1803-1804$ & Hospital Militar de São Paulo & $?$ \\
$\#$ & 1820 & Hospital Militar de Pernambuco & José Eustáquio Gomes \\
Anatomia e cirurgia & 1799 & Bahia & José Xavier de Oliveira Dantas \\
Cirurgia & 1816 & Hospital Militar do Cuiabá & José Maria Guedes \\
\hline
\end{tabular}

Fontes: Santos Filho, 1991, p. 27; Livro de Registro de Instruções, Ordens, Regulamentos..., nº-60 (APMT). 
${ }^{3}$ Alexandre Rodrigues Ferreira in Fontes, 1966.
A proposta e a efetivação de algumas aulas de cirurgia na América portuguesa representavam um grande dilema para a metrópole, ou seja, a influência do pensamento ilustrado e seus efeitos de contestação ao absolutismo e ao sistema colonial. Para as autoridades portuguesas, as inovações só poderiam ser adotadas na colônia desde que não prejudicassem os interesses envolvidos, pois as aberturas da política colonial deveriam se manter nas fronteiras do sistema (Novais, 1991, p. 239).

No governo do marquês de Pombal teve início, em Portugal, um processo de transformações sob influência das Luzes. Entre as medidas tomadas por Pombal, destacou-se a modernização do ensino na Universidade de Coimbra em 1772, até então assentado nos pressupostos da teoria escolástica medieval. De acordo com Fernando Novais (idem, ibidem, p. 224), foi na administração de Dona Maria I, posteriormente ao período pombalino, que tiveram início as maiores aberturas para o pensamento ilustrado. Entretanto, por mais que as idéias se propagassem no ambiente luso-brasileiro, prevalecia a idéia de que a colonização deveria ser mantida, cabendo à metrópole proporcionar benefícios e segurança à sua colônia tão fundamental para o desenvolvimento português.

Nesse período, procedeu-se a todo um levantamento das condições naturais e econômicas do Reino e do Ultramar, aumentando-se os pedidos de exemplares da fauna e da flora brasileiras que pudessem redundar em benefícios para Portugal. Expedições científicas com esse objetivo foram patrocinadas pela Coroa, entre elas a viagem filosófica de Alexandre Rodrigues Ferreira para o Rio Negro e Mato Grosso, entre os anos de 1783 e 1792. Dessa viagem resultou uma monografia sobre as enfermidades endêmicas que assolavam a repartição do Mato Grosso no período. ${ }^{3}$

Em fins dos setecentos e inícios do século XIX, houve no centro da América do Sul, assim como em toda a América portuguesa, uma acentuada preocupação com os locais onde se poderia encontrar e colher a quina, febrífugo de grande eficácia e uso na América Portuguesa, que, assim como outras espécies, enriqueceu a farmacologia européia.

Aquele foi um período em que as pesquisas em ciências naturais ganharam espaço nas tipografias portuguesas. Frei José Mariano da Conceição Veloso foi um dos que divulgaram diversos trabalhos na área, com destaque para as atividades que poderiam ser desenvolvidas no Brasil, como agricultura, criação de animais, instalação de fábricas e mineração. Dentre os textos impressos estavam: Mineiro do Brasil, $O$ fazendeiro do Brasil e Quinografia portuguesa ou coleção de várias memórias (Ferraz, 1997, p. 175).

Justamente em 1799 foram enviadas para a capitania de Mato Grosso, por ordem do príncipe regente, duas remessas de caixotes com diversos exemplares de textos, entre eles Mineralogia de Bergmam, Cultura da caneleira, Quinografia portuguesa e Ofazendeiro do Brasil, trabalhos cujos temas eram fundamentais para o desenvolvimento das atividades produtivas na América portuguesa, em benefício sobretudo da metrópole (Jesus, 2001, p. 110). 
${ }^{4}$ Livro de

Correspondência expedida (ofícios), governo de Caetano Pinto de Miranda, $\mathrm{n}^{\mathrm{o}}$ C-41, APMT
Nesse movimento, as propostas e a aprovação das aulas de cirurgia surgiram como alternativas para atender às queixas dos colonos, não os deixando à mercê das epidemias, pois eles representavam mão-de-obra em potencial e garantia de defesa da colônia (Ribeiro, 1997, p. 123).

No campo da medicina, a alternativa adotada pelo Estado foi a criação de métodos de ensino que limitassem os alunos às questões elementares da arte, concentrando-se no aprendizado prático. Aprovar a existência de uma instituição de medicina na América portuguesa poderia incentivar o sentimento de independência, já motivado pela influência de autores ilustrados. Ao permitir o funcionamento de aulas de cirurgia, o governo metropolitano atendia a algumas das queixas dos colonos. Aqueles que tivessem condições podiam se deslocar para a metrópole, a fim de obter o título de médico.

Em 1768 alguns oficiais de Sabará fizeram uma representação solicitando ao rei Dom José I permissão para implantar um curso teórico e prático de anatomia naquela vila. Alegavam que a falta de socorro e a ação de cirurgiões imperitos eram razões para o estabelecimento da aula. A solicitação foi, contudo, negada (idem, ibidem, p. 123).

Tanto essa proposta quanto as demais aulas, incluindo as de Vila Bela e da Vila do Cuiabá, expressavam a tentativa das autoridades locais em promover o progresso na colônia. Além disso, tratava-se de instruir rapidamente cirurgiões que pudessem deslocar-se para povoados e arraiais distantes dos principais núcleos urbanos afim de atender aos colonos - peças fundamentais como garantia física da colônia e como força de trabalho.

Em 1799, preocupado com essa questão, Joaquim José de Carvalho de Albuquerque Lins informou que a Vila Bela da Santíssima Trindade estava despovoada pelos seguintes fatores: o mau clima e a péssima qualidade da água, o que dificultava a fecundidade das mulheres; o preço cobrado pela Igreja para a realização dos matrimônios; e os infanticídios cometidos pelas mulheres escravas. Para solucionar o problema da baixa fecundidade, Joaquim José de Carvalho propôs o estabelecimento de um hospital com hábeis professores, onde deveriam ser instruídos "alguns Filhos do País, para depois se distribuírem pelos Arraiais e Destacamentos". Aquele seria um hospital público que não atenderia somente aos enfermos, mas instruiria pessoas para lidarem com o curativo. ${ }^{4}$

O ano de 1799 marcou o momento em que parece reduzir o número de profissionais de medicina no centro da América do Sul, sobretudo os que haviam sido deslocados para os fortes militares por ordem do capitão-general, em virtude de um possível ataque espanhol. Tal ameaça mobilizou toda a tropa militar, sinal de que, em fins do século XVIII, a capitania de Mato Grosso, localizada em ponto estratégico da defesa da colônia, vivia sob estado de tensão (Jesus, op. cit., p. 95).

Em situações como essa - em que o número de agentes de cura era reduzido - , caso houvesse enfermidade, os colonos que ficavam nas 
${ }^{5}$ Documentos históricos ultramarinos, microficha 562, Núcleo de Documentação e Informação Histórico Regional (NDIHR). vilas estariam sujeitos à falta de auxílio oficial. Fazia-se necessário, portanto, que se instruíssem homens na arte de aplicar o curativo e que estes estivessem prontos a se deslocar para qualquer ponto da capitania. Procurava-se desse modo garantir o curativo dos soldados dos destacamentos e a sobrevivência da população residente nas vilas.

Complementando a proposta, de acordo com Albuquerque Lins, poderiam ser instruídas "até algumas Mulatas e Pretas ... nos princípios mais essenciais da Arte da Obstetrícia”. Não foram encontradas, até o momento, informações sobre as parteiras que atuaram no centro da América do Sul, nesse período. No entanto, pode-se considerar que as grandes agentes dessa arte eram as mulheres negras e mestiças. Ao fazer referência e indicá-las, Joaquim José demonstrava a flexibilidade tão comum na América portuguesa, em que saberes indígenas, africanos e europeus se mesclaram, fazendo com que, em diversas situações, indivíduos sem formação na arte e curiosos fossem nomeados oficialmente para aplicar o curativo.

Se a aprovação de hospitais públicos visando a 'formação' de indivíduos na arte de curar não era oficializada, outras alternativas deveriam ser adotadas. Em fins do século XVIII urgia inserir a capitania do Mato Grosso nos caminhos da instrução, tendo em seu corpo administrativo novos agentes de cura prontos a se deslocar para qualquer ponto da fronteira.

Seguindo a determinação da carta régia de 1799 — recomendando o envio de jovens para Coimbra a fim de estudarem a arte da engenharia e da medicina -, em junho de 1800 os homens bons da Vila Real do Senhor Bom Jesus do Cuiabá decidiram enviar sete estudantes para a Europa. Iriam instruir-se nas artes e ciências tão úteis à capitania. Dentre eles estava o estudante Antonio Gomes de Oliveira, que se dedicaria aos estudos da arte da cirurgia e seria mantido pelo Senado da Câmara. No ano de 1808 Antonio Gomes suplicou ao rei permissão para voltar à Vila do Cuiabá, para "juntar dinheiro e continuar os estudos", que exigiam depósitos avultados. Não foi possível obter mais informações sobre o estudante. ${ }^{5}$

Por mais deficitárias que tivessem sido as práticas das autoridades em relação à saúde, elas existiram e precisam ser compreendidas no contexto em que foram pensadas. A contratação de agentes de cura, a aquisição de medicamentos, a proposta de construção de hospitais e de implantação de aulas de cirurgia de que trata este artigo são alguns exemplos de práticas que não correspondem ao processo de medicalização ocorrido no século XIX.

\section{Administração da Aula Régia de anatomia e cirurgia de Vila Bela - 1808}

A Corte de Portugal, ao fugir da invasão francesa, aportou no Brasil em 1808, desencadeando aqui transformações que iriam afetar 
as relações entre Estado e sociedade. Nesse período ocorreu a abertura dos portos às nações amigas, com a elevação do Brasil, em 1815, à condição de Reino Unido a Portugal e Algarves. Dom João VI, dando seqüência à política implementada em fins dos setecentos, criou a Academia Real Militar, o curso de Agricultura, a Biblioteca Real, o Museu Real, o Jardim Botânico, as Escolas de Cirurgias em Salvador e no Rio de Janeiro e extinguiu a Junta do Protomedicato, recriando a Fisicatura-Mor, com sede no Rio de Janeiro.

Foi no âmbito dessas ações que os vereadores de Vila Bela da Santíssima Trindade propuseram, em 1808, a criação de uma aula de anatomia e cirurgia. Caso fosse aceita, a proposta atenderia às necessidades dos colonos quanto à presença de pessoal habilitado, bem como asseguraria a permanência de Vila Bela como sede da capitania de Mato Grosso. Contando com uma população diminuta em relação a Vila Real, as autoridades da capital sentiam-se ameaçadas, mesmo porque o próprio capitão-general permanecia mais em Vila Real que em Vila Bela.

De acordo com o plano de aula régia, o governador e capitãogeneral teria amplos poderes, podendo alterar o currículo se achasse necessário e presenciar os exames dos alunos. A aula de anatomia e cirurgia deveria funcionar com um inspetor, um lente, um lente substituto, um guarda-da-sala e doze alunos. A função de lente seria ocupada pelo cirurgião-mor da capitania, que ensinaria e avaliaria os alunos ao final de cada mês. Após as avaliações, o lente deveria entregar um relatório ao capitão-general referente a "habilidade, adiantamento e aplicação" de cada aluno. Isso significava que o capitão-general teria o papel de supervisor da aula.

Humberto Marcílio menciona que o plano foi elaborado pelo cirurgião-mor da capitania, por ordem do capitão-general João Carlos Augusto d'Oeynhausen, em 7 de outubro de 1808. Contudo, além de não se dispor de informação sobre o cirurgião-mor, o plano de que se dispõe foi elaborado pelos vereadores de Vila Bela em 15 de julho de 1808 - o que leva a crer que a proposta dos vereadores foi rejeitada pelo capitão-general, que solicitou novo plano ao cirurgião-mor (alto grau no seio da arte médica, na ausência de um médico).

Segundo o plano apresentado pelos vereadores, na ausência do cirurgião-mor um dos cirurgiões do partido militar da capitania assumiria a função, sendo nomeado pelo capitão-general. O guarda ficaria incumbido de limpar a sala e, na sua ausência, seria substituído por um enfermeiro ou praticante do hospital militar. Do mesmo modo, a sala destinada às lições estaria localizada no quartel militar, servindo ao mesmo tempo para as operações anatômicas. Nela haveria armários ou gavetas para guardar os instrumentos, bancos para os alunos, cadeira e mesa com gaveta para o lente e uma mesa grande para as operações. Na porta da sala estaria fixada uma tabela com o horário das aulas. 
${ }^{6}$ Manuscrito avulso, lata 1793 B, APMT.

${ }^{7}$ Plano de Aula Régia de Anatomia e Cirurgia de Vila Bela [...], op. cit.
${ }^{8}$ Idem.
A aula teria como sede uma das salas do quartel militar onde estava localizado o hospital militar de Vila Bela. Basicamente todas as aulas implantadas na América portuguesa, desde fins dos setecentos, tiveram como sede o hospital militar. Desde a segunda metade do século XVIII, esses hospitais serviram como espaço de instrução de cirurgiões, boticários e enfermeiros, que aprendiam a lidar com a arte por meio do saber empírico, sendo acompanhados por um cirurgião aprovado que os examinava. Assim ocorreu com o soldado dragão Antonio de Almeida Campos, em 1793, nomeado pelo capitãogeneral para praticar a cirurgia de acordo com a direção do cirurgião do partido militar. ${ }^{6}$

A despesa da aula ficaria sob responsabilidade da Câmara de Vila Bela. Os vereadores alegavam que existia nos cofres uma avultada quantia destinada, pelas ordens régias, para a "educação da mocidade" que não tinha sido empregada, sendo a aula um bem útil a povo, pois:

... por falta de conhecimentos próprios tem levado milhares de vida nesta capitania e é por isso que lembrando-me vários outros, a todos me parece preferível o estabelecimento de uma Aula de Anatomia e Cirurgia.?

Em 1772, o marquês de Pombal estabelecera o subsídio literário, destinado à manutenção das escolas públicas. No entanto, em 1795, foi publicada uma nova carta régia sobre o tema, transferindo o controle do subsídio para a Junta de Finanças, devido a problemas no valor dos produtos, desvios de fundos e até mesmo falta de arrecadação do imposto. O subsídio literário ficou em vigor até 1816 (Almeida, 1989, p. 38). Era com o capital acumulado desse imposto que a aula seria implantada em Vila Bela.

As autoridades locais almejavam inserir a atenção ao centro da América do Sul, especificamente Vila Bela, no rol de medidas tomadas por Dom João VI quando chegou ao Brasil. Além disso, estava em jogo a continuidade da capital de Mato Grosso em Vila Bela. A incerteza dominava as autoridades locais, que já deparavam com um decréscimo populacional e temiam ver os cofres públicos esvaziados.

\section{Alunos e estrutura curricular}

A aula de anatomia e cirurgia de Vila Bela teria doze alunos, apresentados pela Câmara ao capitão-general, que os escolheria a partir dos seguintes critérios:

1ํ) que nunca os alunos terão mais de quinze, nem menos de dez anos de idade;

$2^{\circ}$ ) que saberão ler, escrever e contar;

$\left.3^{\circ}\right)$ que serão preferidos os filhos de viúvas e geralmente os de pais mais indigentes, de que lhe faz classe indiferentemente, contanto que fossem forros. ${ }^{8}$ 
Em uma região de fronteira escravista e mineradora, ameaçada constantemente pelas enfermidades, tornar-se cirurgião poderia ser um meio de alcançar uma posição privilegiada diante de outras especialidades da arte de curar; em primeiro lugar, porque o número de médicos era reduzido, mas também porque era muito marcante a estratificação salarial no interior da arte. Ao aceitar a presença de jovens forros, as autoridades locais favoreciam o alargamento da área cirúrgica, adaptando-a em um novo meio, cuja população livre era constituída predominantemente de negros e mulatos.

No manuscrito transcrito por Humberto Marcílio (op. cit., p. 30) sobressaem algumas diferenças nos critérios de seleção dos alunos:

$1^{\circ}$ ) os alunos deveriam saber ler e escrever correntemente;

$2^{\circ}$ ) não ter defeitos ou lesões que embaraçassem o exercício desta arte;

$3^{\circ}$ ) ter entre quatorze e vinte anos, podendo exceder a esta idade aqueles que tiverem alguns dos requisitos atendíveis.

Assim sendo, suprimiam-se a aptidão de contar, a preferência por filhos de viúvas e pais indigentes e aumentava-se a faixa etária, incluindose o aspecto físico.

Quanto à estrutura curricular, na transcrição de Humberto Marcílio as disciplinas são apenas citadas, não havendo maiores informações sobre a ordem interna de cada uma, bem como sobre a procedência e conservação dos cadáveres. A aula teria uma duração de quatro anos, sendo dividida em "estudo teórico e prático de anatomia" e "cirurgia". Entretanto, chama a atenção a ausência do estudo da obstetrícia, que nove anos antes havia sido proposta devido o decréscimo populacional. De acordo com Humberto Marcílio, as disciplinas estavam distribuídas do seguinte modo:

Dois anos para anatomia:

$1^{\circ}$ ano: oito meses para osteologia e quatro meses para miologia;

$2^{\circ}$ ano: três meses para angiologia, três meses para nevrologia e seis meses para splancnologia;

3o ano: [... ] demonstrações anatômicas, explicações fisiológicas e estudo da cirurgia teórica;

$4^{\circ}$ ano: medicina operatória ou cirurgia prática. Haverá aulas quatro dias na semana, a saber, segundas, terças, quintas e sextas-feiras, de manhã logo depois de rendida a Parada; nos últimos sábados de todos os meses haverá uma sabatina ou recapitulação de todos os atrasados; haverá também um mês de férias no ano, findo o que se abrirá a aula, havendo nesse dia uma oração de sapiência ou alguma tese, logo que hajam praticantes em estado

${ }^{9}$ Aula de Anatomia de Vila Bela, apud Marcílio, op. cit., p. 30. de a defender.'

Ainda cabia aos estudantes praticantes do último ano assistir os enfermos todos os dias, ajudando o professor no tratamento dos 
${ }^{10}$ Plano de Aula de Anatomia e Cirurgia de Vila Bela, op. cit.
${ }^{11}$ Sobre essas práticas em fins do século XVIII, ver Ribeiro, 1998. doentes. Um dos praticantes seria obrigado a tomar conta da aula, tratando do asseio e da limpeza dos instrumentos e dos cadáveres.

No plano proposto pelos vereadores não constava a estrutura curricular, somente a informação de que haveria "demonstrações e operações", havendo em seguida uma preocupação com a sala de aula. Quanto ao material, como já foi mencionado, este ficaria sob responsabilidade da Câmara, que não faria:

$1^{\text {o) }}$ a que for necessária para o decente preparo da sala;

$2^{\circ}$ ) a que for necessária para dar um vestido completo e uniforme a cada um dos doze alunos matriculados;

$\left.3^{\circ}\right)$ a que fornecessem para papel as apostilas das suas lições. ${ }^{10}$

De acordo com o plano apresentado por Humberto Marcílio, os alunos receberiam apostila, por "haver ... falta de livros necessários para estes estudos", dado que se aproxima àquele apresentado pelos vereadores.

Com a reforma da Universidade de Coimbra no ano de 1772 , determinou-se que seriam elaborados compêndios a fim de evitar a prática comum das "sebentas ou apostilas", registros de aulas copiados pelos alunos e passados de mão em mão (Ferraz, op. cit., p. 68). Embora se afirmasse que havia falta de livros para os estudos, esse argumento não deve ser tomado como absoluto, pois ele pode ocultar a existência de 'livrarias' e de comércio livreiro no interior da vilas coloniais. Há registros de livros, inclusive de cirurgia, nas bibliotecas particulares da Vila Real do Senhor Bom Jesus do Cuiabá desde a primeira metade dos setecentos (Rosa, 1996, p. 61).

Seis meses após a abertura da aula, haveria um exame público que contaria com a presença do capitão-general e dos vereadores. Os alunos reprovados seriam "despedidos", por demonstrarem pouca habilidade, aplicação e talento. No lugar destes, outros seriam admitidos e matriculados. Para despertar zelo e aplicação dos alunos seriam concedidos prêmios aos que mais se destacassem.

Desde 1777 foram criados prêmios ou "partidos" na Universidade de Medicina de Coimbra, para incentivar o estudo, pois a redução dos alunos poderia trazer graves conseqüências para universidade e para o povo (idem, 1997, p. 68). Anos depois, tal medida seria proposta na América portuguesa, com a mesma finalidade.

O plano de aula de anatomia e cirurgia de Vila Bela possuía em seu conteúdo pequenos vestígios de elementos de ruptura e de permanência da arte médica. O estudo de anatomia com uso de cadáveres, reimplantado em Coimbra após 1772, significou um rompimento com a medicina escolástica que condenava tal prática. A proposta de estudo de músculos e vísceras, entre outros, presente no plano de aula de Vila Bela, demonstra, ainda que teoricamente, a adoção de saberes em que o corpo passaria a ser o centro de observação, o local onde se deveria buscar a causa das enfermidades - até meados do século XVIII atribuída à influência dos astros e do sobrenatural. ${ }^{11}$ 
12 Regulamento Provisional para a Aula de Cirurgia na Vila Real do Senhor Bom Jesus do Cuiabá, op. cit.

\section{Aula de cirurgia na Vila Real do Senhor Bom Jesus do Cuiabá - 1816}

O regulamento provisional para a Aula de Cirurgia do Cuiabá foi aprovado pelo capitão-general João Carlos Augusto d'Oeynhausen em 16 de dezembro de 1816, sendo a função de lente ocupada inicialmente pelo cirurgião-mor da capitania, José Maria Guedes.

Assim como o plano de Vila Bela, o regulamento ficaria sob responsabilidade do capitão-general; no entanto, ele permitia ao cirurgião-mor estabelecer um sistema de disciplina adequado, pois reconhecia que José Maria Guedes tinha "perfeito conhecimento do sistema de disciplina das mais Aulas desta natureza"12, indício do conhecimento por parte do capitão-general de outras aulas de cirurgia na América portuguesa.

Ao final de cada aula, o cirurgião deveria dar conta do procedimento de cada um dos discípulos e de sua aplicação. Ao propor a aula, o capitão-general referiu-se aos problemas e obstáculos que o cirurgiãolente poderia encontrar. Contudo, não sabemos a que dificuldades ele se referia.

Enquanto o plano de Vila Bela transcrito por Humberto Marcílio mencionava a estrutura curricular, com as respectivas disciplinas e duração do curso, no plano de Cuiabá, constituído por 13 tópicos, esses elementos não eram referidos. A preocupação concentrava-se nas atribuições dos lentes e dos alunos, que deveriam seguir rigidamente o horário.

Assim como o plano de Vila Bela e as demais aulas da América portuguesa, a aula de cirurgia inicialmente iria funcionar em uma das salas do quartel militar, local em que funcionava o hospital militar. Os alunos deveriam estar presentes às oito horas da manhã para a chamada, ficando responsável por tal atividade um dos alunos, que informaria ao cirurgião-lente sobre aquele que faltasse. Em seguida, um oficial do estado deveria dirigir-se até a casa do faltoso e buscá-lo. Caso estivesse doente, o aluno deveria enviar por escrito as razões de sua ausência antes do início da aula, pois se desse:

... essa parte só quando o forem procurar não será havida por verdadeira e não só se notará a falta, mas ficará o tal sujeito a mesma que se regular para as faltas sem causa..$^{13}$

Era importante estabelecer as presenças e as ausências, saber onde e como encontrar os indivíduos, medir qualidades ou méritos.

Enquanto no Plano de Vila Bela a visita aos enfermos deveria ser realizada no último ano, no regulamento de Cuiabá não há essa informação, o que leva a supor que a visita seria realizada de imediato. Os alunos eram obrigados a fazer todo o curativo que o cirurgião mandasse, e a visita duraria das oito até as nove horas da manhã, havendo em seguida, até as 11 horas, a aula teórica. 
14 Idem.

15 Idem.
Para melhor aproveitamento da segunda parte da aula, deveria o cirurgião-mor integrar o melhor que pudesse "a teoria com a prática aplicando o que nas suas lições explicar a prática do curativo do hospital" ${ }^{\prime 14}$. Percebe-se neste item a preocupação entre teoria e prática, que em Portugal entrou em cena após a reforma do ensino de 1772. As aulas seriam realizadas todos os dias da semana, à exceção das quintas-feiras, porém, nas semanas em que houvesse um ou mais dias santos a aula transcorreria normalmente na quinta-feira.

Os alunos seriam dispensados de todo serviço e, quando considerados aptos pelo cirurgião-mor, poderiam ser examinados com toda a publicidade e solenidade, de modo a merecerem o aplauso dessa aplicação. Se desejasse abandonar as aulas, o aluno deveria ter permissão do cirurgião-mor e do capitão-general, pois ele estava obrigatoriamente destinado a uma missão.

Em 12 de julho de 1817, o cirurgião-mor José Maria Guedes recebeu a confirmação da aprovação real da aula de cirurgia, que desde dezembro de 1816 funcionava interinamente, pela necessidade de formação de indivíduos para aplicar o curativo. Assim sendo, as ordens estabelecidas continuariam em vigor, acrescidas de outras. De acordo com a ordem régia, os alunos matriculados seriam obrigados a freqüentar a aula, não gozando de dispensa em hipótese alguma. As informações sobre o encaminhamento da aula deveriam ser apresentadas ao capitão-general no verso do mapa do hospital, onde seriam anotados: falta de freqüência ou de aplicação, mau procedimento do aluno e respectiva advertência. Se, após as advertências, o aluno não corrigisse seu comportamento, o cirurgião-mor poderia puni-lo com prisões, conforme a gravidade da culpa, e somente ele poderia soltá-lo: prisão da $1^{\underline{a}}$ classe, na enfermaria no 3 do hospital; prisão da $2^{a}$ classe, na casa do Almoxarifado da Casa Pia de São Lázaro, a cargo do cabo João Marques; prisão da $3^{a}$ classe, no calabouço. ${ }^{15}$

$\mathrm{Na}$ ordem régia não há referência sobre as faltas que levariam à prisão; apenas se mencionam as faltas não justificadas, que se consideravam oriundas de preguiça e ociosidade. Do mesmo modo que no plano de Vila Bela, o regulamento de Cuiabá estabelecia prêmios para os melhores alunos, conforme a portaria de 4 de junho de 1817, e dividiam-se em três classificações:

TABELA 2

VALORES DOS PRÊMIOS DA AULA DE CIRURGIA DE CUIABÁ

\begin{tabular}{ccc}
\hline PRÊMIO & POR MÊS & POR ANO \\
\hline $1^{\circ}$ & 90.600 & 115.200 \\
$2^{\circ}$ & 20.400 & 570.600 \\
$3^{\circ}$ & 20.000 & 280.800 \\
$4^{\circ}$ ) Plena aprovação & -- & 380.40 \\
\hline
\end{tabular}

Fonte: Livro de registro de instruções, ordens, regulamentos e resoluções, nº660 (APMT). 
Não se encontraram informações sobre o pagamento desses prêmios, bem como sobre sua procedência. Em Vila Bela, seriam pagos pelo subsídio literário, extinto em 1816, ano de criação da aula de cirurgia de Cuiabá.

Embora o regulamento de Cuiabá não forneça informações sobre a estrutura curricular, existem nele alguns pontos semelhantes ao plano de Vila Bela e demais aulas da América portuguesa: supervisão direta do capitão-general, pagamento de prêmios, dias letivos e exame geral. Em ambas as propostas, cada indivíduo teria sua função delimitada e baseada em uma hierarquia interna, figurando em primeiro plano o capitão-general, depois o cirurgião-mor, o oficial do estado e, por último, os alunos. Entre estes haveria uma divisão de tarefas, que iam da fiscalização mútua até a organização dos materiais.

Tudo deveria correr dentro da normalidade e, para tal, a rigidez do horário, o bom emprego do tempo, as micro penalidades e o exame, iniciado com as visitas no hospital, constituíam toda uma série de processos sutis (Foucault, 1997, p. 133).

Algumas diferenças podem ser percebidas entre os dois planos: no da Vila Real não havia o estudo de anatomia, disciplina pertencente aos dois primeiros anos do curso de anatomia e cirurgia de Vila Bela, indício do desejo de transmissão de noções de medicina aos alunos. No entanto, no regulamento de Cuiabá a preocupação com o controle do tempo e dos corpos era mais intensa que no de Vila Bela. A vigilância sobre os alunos não se limitava ao espaço do hospital, abrangendo a casa e os comportamentos nos momentos alheios à aula. Era necessário evitar que os alunos se dispersassem e se entregassem à ociosidade e à preguiça.

16 Francisco Xavier de Azevedo a Francisco de Paula Magessi. Rio de Janeiro, 24.1.1821. Livro de registro de avisos, cartas, provisões e decretos, nº C-64, fólio 43, APMT.

\section{Cirurgião-lente e alunos da aula de anatomia e cirurgia de Cuiabá}

José Maria Guedes, cirurgião-mor da capitania de Mato Grosso, exerceu papel de lente entre os anos de 1816 e 1817. Pela função, deveria gozar de todas as honras, isenções, privilégios e liberdades, recebendo um soldo anual de sessenta mil-réis. O cirurgião, por volta de 1819, solicitou licença para se deslocar para o Rio de Janeiro, a fim de tratar da saúde. Por autorização real de 1821, poderia embarcar como cirurgião no navio-hospital da esquadra com destino a Lisboa. Além disso, desejava retornar ao Reino para fazer uso das Caldas da Rainha. ${ }^{16}$

Por ordem de 24 de junho de 1822, no entanto, não pôde deixar o Brasil. No segundo semestre de 1821, houve várias ordens reais informando que todo funcionário público e militar afastado de seus cargos e do local de trabalho deveria assumir o posto imediatamente. Assim, José Maria Guedes deveria retornar a Cuiabá, salvo se 
${ }^{17}$ Regulamento Provisional para a Aula de Cirurgia na Vila Real do Senhor Bom Jesus do Cuiabá, op. cit.

${ }^{18}$ Relação dos alunos da Aula Régia de Cirurgia aprovada por Sua Majestade. Vila do Cuiabá, 20.12.1817. Livro de Registro de Instruções, Ordens, Regulamentos, fólio 147, APMT. comprovasse sua impossibilidade. Parece que o cirurgião não foi bem-sucedido em suas justificativas, tanto que, em 27 de novembro de 1821, queixava-se de não ter conseguido viajar. O cirurgião Antonio Luiz Patrício da Silva Manso oferecia-se para se deslocar para Mato Grosso, sem receber para essa função qualquer vencimento. ${ }^{17}$

Enquanto José Maria Guedes esteve fora e sem substituto, ficou responsável pelas questões relacionadas à medicina e à saúde o cirurgiãomor da tropa de linha da capitania, José Alexandrino Dias de Moura, que tinha um vencimento anual de trezentos mil-réis. Por ordem do então capitão-general, em fevereiro de 1819, José Alexandrino deveria informar sobre o estado da aula de cirurgia, os indivíduos que a haviam freqüentado e seu progresso. Até o momento não nos foi possível localizar o relatório do cirurgião-mor.

Quanto aos alunos matriculados, assim como em Vila Bela, eram 12. Três deles pertenciam à Companhia de Dragões: o anspeçada de dragões José Gonçalves e os soldados Manoel Pinto de Miranda e Manoel da Silva Novais. Mesmo freqüentando as aulas, eles recebiam um soldo mensal de 4.800 réis. $^{18}$ A presença dos soldados, comum na arte médica dos setecentos, demonstra a preocupação do Estado com a formação de quadros dirigentes na administração e no exército, bem como uma forma de proteção aos estudos destinados ao comércio e à arte de curar.

Em 1819, ainda na gestão do cirurgião José Alexandrino, foram identificadas petições de alunos pleiteando isenção de participar das aulas. Francisco Pereira de Moraes Jardim, por exemplo, solicitou que seu filho fosse "riscado da Aula de Cirurgia", porém não informava a razão do pedido. Os dois pareceres deveriam ser dados pelo cirurgiãomor.

Esses dados são pequenos fragmentos que abrem espaço para uma investigação aprofundada sobre as aulas de anatomia e cirurgia na América portuguesa. Reorganização de hospitais, vacinação, preocupação com a farmacologia — expressas em livros e fundamentadas com as viagens filosóficas - e criação de aulas de anatomia e cirurgia de que trata este artigo foram, portanto, práticas, que deram continuidade a uma política de saúde ampliada e influenciada pelo movimento de Ilustração, a partir da segunda metade dos setecentos no Brasil. 


\section{REFERÊNCIAS BIBLIOGRÁFICAS}

Almeida, José

Ricardo Pires de 1989

Ferraz, Márcia Helena 1997

Ferreira, Alexandre Rodrigues

1966

Foucault, Michel 1997

Jesus, Nauk Maria de 2001

Marcílio, Humberto 1963

Novais,

Fernando Antonio 1991

Ribeiro, Márcia Moisés 1997

Rosa, Carlos Alberto 1996

Santos Filho, Licurgo 1991
História da instrução pública no Brasil (1500-1889).

São Paulo/Brasília, Educ/Inep-MEC.

As ciências em Portugal e no Brasil (1772-1822): o texto conflituoso da química. São Paulo, Educ.

'Enfermidades endêmicas da capitania de Mato Grosso'. Em Glória Marly Fontes. Alexandre Rodrigues Ferreira: aspectos de sua vida e obra. Amazonas, Conselho Nacional de Pesquisa, Instituto Nacional de Pesquisa da Amazônia.

Vigiar e punir: história da violência nas prisões. Petrópolis, Vozes.

Saúde e doença: práticas de cura no centro da América do Sul (1727-1808).

Dissertação de mestrado, Departamento de Pós-Graduação em História/UFMT, Cuiabá.

História do ensino em Mato Grosso. Cuiabá, Secretaria de Educação, Cultura e Saúde de Mato Grosso.

Portugal e Brasil na crise do antigo sistema colonial.

São Paulo, Edusp.

A ciência dos trópicos. A arte médica no Brasil do século XVIII. São Paulo, Hucitec.

A Vila Real do Senhor Bom Jesus de Cuiabá: vida urbana em Mato Grosso no século XVIII: 1722-1808.

Tese de doutoramento, Universidade de São Paulo, São Paulo.

História geral da medicina brasileira.

Vol. 1.São Paulo, Edusp.

Recebido para publicação em outubro de 2001.

Aprovado para publicação em março de 2003 